\title{
GAMBARAN PENGETAHUAN DAN SIKAP REMAJA PUTRI TERHADAP ABORSI
}

\author{
Mimatun Nasihah* \\ *Dosen Program Studi Diploma III Kebidanan Universitas Islam Lamongan \\ Jl Veteran No 53 A Lamongan
}

\begin{abstract}
ABSTRAKS
Kasus aborsi adalah fenomena sosial yang tak kunjung ada solusi pemecahan masalahnya. Faktor penyebab terjadinya aborsi adalah ekonomi, karir/Sekolah, penundaan usia perkawinan, pengetahuan, sikap, incest, menarche, pemerkosaan.

Desain penelitian ini adalah deskriptif dengan pendekatan survey, populasinya adalah semua remaja putri di MAN Lamongan kelas XI IPS. Pengambilan sampel dengan metode total sampling dengan jumlah sampel 40 responden. Data dikumpulkan dari responden dengan menggunakan kuesioner. Tujuan dari penelitian ini adalah untuk mengetahui gambaran pengetahuan dan sikap remaja putri terhadap aborsi di Madrasah Aliyah Negeri Lamongan.

Dari pengumpulan data pengetahuan responden diperoleh 17 responden (42.5\%) berpengetahuan kurang, 13 responden $(32.5 \%)$ berpengetahuan cukup dan 10 responden $(25 \%)$ berpengetahuan baik.

Dari pengumpulan data sikap responden diperoleh 23 responden $(57.5 \%)$ bersikap negatif, 17 responden $(42.5 \%)$ bersikap positif.

Diharapkan institusi yang terkait dengan masalah kesehatan reproduksi khususnya remaja putri dapat berkerjasama dengan media elektronik khususnya televise dalam menyiarkan pembelajaran tentang aborsi dan bahayanya.
\end{abstract}

\section{Kata kunci : Pengetahuan, Sikap, Remaja Putri, Aborsi}

\section{PENDAHULUAN}

$\begin{array}{rrr}\text { Aborsi merupakan } & \text { semua } \\ \text { upaya } \quad \text { atau tindakan } & \text { yang }\end{array}$ dimaksudkan untuk menghentikan kehamilan baik dilakukan melalui pertolongan orang lain sepeti dokter, dukun bayi, dukun pijat dan sebagainya, maupun dilakukan sendiri dengan cara meminum obatobatan atau ramuan tradisional (Wiknjosastro, Gulardi dalam Ulfah,M. dan Ghalib A, 2004).

Aborsi adalah terminasi (penghentian) kehamilan yang disengaja (abortus provokatus) yakni kehamilan yang diprovokasi dengan berbagai macam cara sehingga terjadi pengguguran. Akibat dorongan yang mendesak untuk mengakhiri kehamilan tersebut sejumlah remaja tanpa memikirkan risiko yang ditimbulkan, memilih aborsi sebagai pilihan terakhirnya (Dianawati, 2003).

Namun tindakan aborsi tersebut mengandung risiko yang cukup tinggi. Apalagi bila dilakukan tidak sesuai dengan standar profesi medis (Munajat N, 2000). Aborsi seperti itu dapat menyebabkan infeksi disertai dengan perdarahan bahkan kematian. Risiko tersebut akan lebih tinggi bila terjadi pada usia remaja dan juga akan 
berdampak pada kesehatan reproduksinya. Aborsi pada usia remaja terjadi antara lain karena kehamilan diluar nikah atau kehamilan yang tidak diinginkan (KTD).

Kesehatan reproduksi remaja telah menjadi isu global. Hampir seluruh Negara menjadikan masalah ini sebagai salah satu program utama. Berdasarkan data, kondisi kesehatan reproduksi remaja cenderung menurun dan aborsi dikalangan remaja cenderung meningkat (Purbaningsih, 2004).

Berdasarkan sumpah

Hippocrates yang berbunyi "saya tidak akan memberikan obat yang mematikan kepada siapapun walau atas perintah atau nasihat orang lain dan selalu dengan cara yang benar. Juga saya tidak akan memberikan wanita alat untuk menggugurkan kandungannya, dan saya akan memegang teguh kemurnian dan kesucian hidup saya maupun ilmu saya. Saya tak akan menggunakan pisau, bahkan alat yang berasal dari batu pada penderita (untuk percobaan), akan tetapi saya akan menyerahkan kepada ahlinya". Olehkarena itu berdasarkan sumpah Hippocrates petugas kesehatan khususnya dokter tidak boleh melakukan aborsi. Indonesia merupakan salah satu Negara yang melarang praktek aborsi. Hal ini ditegaskan dalam UU kesehatan No. 23 tahun 1992. Bahkan KUHP dengan tegas melarang tindakan aborsi apapun alasannya kecuali untuk menyelamatkan nyawa si ibu sebagaimana diatur dalam pasal 346, pasal 347, pasal 348, pasal 349 (Maria, 2006). Di satu pihak aborsi dianggap ilegal dan dilarang oleh agama sehingga masyarakat cenderung menyembunyikan kejadian aborsi, dilain pihak aborsi terjadi di masyarakat.

Dari situs http://situs.kesrepro.info, diakes tanggal 10 april 2015 World health Organization (WHO) di tahun 2012, terdapat sekitar 210 juta yang hamil, 46 juta wanita diantaranya melakukan aborsi dan hampir setengahnya melalui cara yang tidak aman (sekitar 20 juta). Diperkirakan 15 juta remaja setiap tahunnya hamil, $60 \%$ diantaranya tidak dikehendaki.

Di Indonesia, $11 \%$ dari kematian maternal akibat aborsi yang tidak aman (unsaf abortion) menurut data WHO, pada tahun 2010 (Wilopo, 2011). Estimasi national menyatakan setiap tahun terjadi dua juta kasus aborsi di Indonesia. Terdapat 43 kasus aborsi peseratus kelahiran hidup, terdapat 53.783.717 perempuan usia 15-49 tahun atau 37 kasus aborsi pertahun perseribu perempuan usia 15-49 tahun (berdasarkanCrude Birth Rate (CBR) sebesar 23 perseribu kelahiran hidup).

Dari berbagai penelitian menunjukkan, perilaku seksual pada remaja mempunyai korelasi dengan sikap remaja terhadap seksualitas. Penelitian tentang perilaku seksual di empat kota menunjukkan 3,6\% remaja di kota Medan, 8,5\% remaja di kota Jogjakarta, 3,4\% di kota Surabaya,serta $31,1 \%$ remaja di kota Kupang telah terlibat hubungan seks secara aktif. Penelitian juga menemukan 33,5\% responden lakilaki di kota Bali pernah berhubungan seks, sedangkan di desa Bali sebanyak 23,6\% laki-laki. Di Jogjakarta, kota sebanyak $15,5 \%$ sedangkan di desa sebanyak $0,5 \%$ (Tito, 2001).

Berdasarkan data yang diperoleh dinas kesehatan lamongan 
bagian kesehatan reproduksi didapatkan bahwa terdapat beberapa remaja putri yang melakukan aborsi akibat kehamilan tidak dikehendaki di kabupaten Lamongan. Dapat disimpulkan pengetahuan remaja putri terhadap masalah pengaturan kesehatan reproduksi dan seksual masih kurang.

Dari berbagai survey di Indonesia mendukung penemuan bahwa akar masalah dibalik alasan melakukan aborsi adalah penundaan dan peningkatan usia perkawinan serta semakin dininya usia menstruasi pertama, minimnya pengetahuan tentang prilaku seksual yang dapat menyebabkan kehamilan, kehamilan yang diakibatkan pemerkosaan, alasan karir atau masih sekolah, persoalan ekonomi, kehamilan karena incest (Wilopo dan Notoatmojo, 2005).

Semakin pesatnya kemajuan ilmu teknologi yang menampilkan informasi yang berkonotasi pornografi yang bersumber dari berbagai media cetak (misalnya : Koran, majalah, tabloid, dan sebagainya) dan juga media elektronik (misalnya : internet yang lewat jejaring social facebook, Short Massage Sent/SMS, VCD porno dan sebagainya) perlu disikapi dalam menerima informasi tersebut khususnya para remaja yang masih rentan atau peka terhadap "hal-hal baru" tersebut.

Para siswa khususnya remaja putri di MAN Lamongan tentu saja tidak luput dari arus informasi yang semakin gencar tersebut. Tanpa adanya atau tanpa dibekalinya remaja dengan pengetahuan maupun sikap yang baik terhadap informasi tersebut, hal ini tentu sangat berpeluang terjadinya seks pranikah yang berakibat pada kejadian kehamilan yang tidak dikehendaki dan berlanjut pada aborsi di sekolah tersebut. Pengetahuan dan sikap para remaja putri perlu mendapat perhatian yang ekstra agar para remaja tersebut tidak terjerumus pada hal-hal yang tidak diinginkan akibat dampak dari seks bebas yang berkaitan dengan informasi yang diterima melalui media dimaksud dengan melakukan budaya "cobacoba" dalam pergaulan sehari-hari.

Berdasarkan latar belakang di atas maka perlu dilakukan penelitian tentang pengetahuan dan sikap remaja putri terhadap aborsi di MAN Lamongan.

\section{PEMBAHASAN}

Pada bab ini akan membahas mengenai data penelitian yang meliputi data umum dan data khusus. Pengambilan data dilakukan pada bulan Juli 2015. data yang digunakan adalah data primer yang diambil secara langsung dari responden melalui lembar kuesioner di Madrasah Aliyah Negri Lamongan sebanyak 40 siswi dengan melakukan permohonan persetujuan (informed consent) terlebih dahulu. Data yang diperoleh kemudian direkapitulasi dan diolah.

\subsection{Hasil Penelitian}

Berdasarkan

hasil

pengumpulan data primer mengenai gambaran pengetahuan dan sikap remaja putri terhadap aborsi pada siswi MAN Lamongan kelas XI IPS tahun 2015 sebanyak 40 responden. Diperoleh data sebagai berikut :

\subsubsection{Data Umum}

Berdasarkan hasil penelitian distribusi frekuensi responden, menurut umur, kelas dan sumber 
informasi aborsi dapat dilihat pada table di bawah ini :

\section{Gambaran Umum Lokasi Penelitian}

MAN Lamongan didirikan pada tahun 1980 MAN Lamongan ini terletak di jalan Veteran Lamongan.

Luas sekolah ini yaitu 1000

M yang dilengkapi fasilitas-fasilitas yang menunjang untuk proses belajar mengajar seperti ruang/local belajar, ruang laboratorium, ruang perpustakaan, tempat/sarana olahraga dan ruang UKS. Tenaga mengajar berjumlah 62 orang terdiri guru tetap serta tenaga tata usaha 8 orang. jumlah siswa seluruhnya 651 orang yang terdiri dari 16 lokal, siswa kelas satu 6 lokal, siswa kelas dua 5 lokal, siswa kelas tiga 5 lokal.

\section{Karasteristik Responden Umur}

Tabel 2.1. Distribusi Responden Berdasarkan Umur di MAN Lamongan tahun 2015.

\begin{tabular}{|c|c|c|c|}
\hline No & Umur & $\mathbf{N}$ & \% \\
\hline $\mathbf{1}$ & $15-16$ & 15 & 37.5 \\
$\mathbf{2}$ & $17-19$ & 25 & 62.5 \\
\hline \multicolumn{2}{|c|}{ Total } & 40 & 100 \\
\hline
\end{tabular}

Dari tabel 2.1 di atas diketahui sebagian besar responden berumur 17-19 tahun (62.5 \%) responden dan sebagian lagi berumur 15-16 tahun $(37.5 \%)$ responden.

\section{Karasteristik Responden Sumber Informasi}

Tabel 2.2 Distribusi Responden Berdasarkan Sumber Informasi tentang Aborsi di MAN Lamongan tahun 2015.

\begin{tabular}{|l|l|l|l|}
\hline No & Sumber & N & $\%$ \\
\hline
\end{tabular}

\begin{tabular}{|l|c|c|c|}
\hline & Informasi & & \\
\hline $\mathbf{1}$ & Orangtua & 5 & 12.5 \\
$\mathbf{2}$ & Kakak/Saudara & 3 & 7.5 \\
$\mathbf{3}$ & Guru & 3 & 7.5 \\
$\mathbf{4}$ & Teman sebaya & 3 & 7.5 \\
$\mathbf{5}$ & Petugas kesehatan & 3 & 7.5 \\
$\mathbf{6}$ & Tokoh agama & 3 & 7.5 \\
$\mathbf{7}$ & Media cetak & 8 & 20.0 \\
$\mathbf{8}$ & Media elektronik & 12 & 30.0 \\
\hline \multicolumn{2}{|r|}{ Total } & 40 & 100 \\
\hline
\end{tabular}

Dari tabel di atas diketahui sebagian besar sumber informasi yang didapat responden dari media elektronik yaitu $12 \quad(30.0 \%)$ responden dan sebagian lagi diperoleh dari media cetak 12 (20.0 $\%)$, orangtua 5 (12.5\%), kakak/saudara 3 (7.5\%), guru 3 $(7.5 \%)$, teman sebaya $3(7.5 \%)$, petugas kesehatan 3 (7.5\%), tokoh agama $3(7.5 \%)$ responden.

\subsubsection{Data Khusus}

\section{Data Pengetahuan Responden}

Berdasarkan hasil penelitian diketahui distribusi frekuensi responden menurut pengetahuan remaja putri terhadap aborsi di MAN Lamongan kelas XI IPS sebanyak 40 siswi pada tahun 2015, dapat dilihat pada table di bawah ini :

Tabel 2.3 Distribusi Responden Berdasarkan Pengetahuan Remaja Putri Terhadap Aborsi di MAN Lamongan tahun 2015.

\begin{tabular}{|c|c|c|c|}
\hline No & $\begin{array}{c}\text { Pengetahuan } \\
\text { Remaja } \\
\text { Putri } \\
\text { Terhadap } \\
\text { Aborsi }\end{array}$ & N & $\%$ \\
\hline 1 & Baik & 10 & 25 \\
2 & Cukup & 13 & 32,5 \\
3 & Kurang & 17 & 42,5 \\
\hline & Total & 40 & 100 \\
\hline
\end{tabular}


Dari tabel di atas dapat dilihat bahwa sebagian besar remaja putri di kelas XI IPS Madrasah Aliyah Negeri Lamongan kurang mengetahui pengetahuan tentang aborsi sebanyak 17 responden $(42,5$ $\%$ dan sebagian kecil berpengetahuan baik sebanyak 10 responden $(25 \%)$.

\section{Data Sikap Responden}

Berdasarkan hasil penelitian diketahui distribusi frekuensi responden menurut pengetahuan remaja putri terhadap aborsi di MAN Lamongan kelas XI IPS 1 dan XI IPS 2 sebanyak 40 siswi pada tahun 2015, dapat dilihat pada table di bawah ini :

Tabel 2.4 Distribusi Responden Berdasarkan Sikap Remaja Putri Terhadap Aborsi di MAN Lamongan tahun 2015.

\begin{tabular}{|c|c|c|c|}
\hline No & $\begin{array}{c}\text { Sikap Remaja } \\
\text { Putri } \\
\text { Terhadap } \\
\text { Aborsi }\end{array}$ & $\mathbf{N}$ & $\boldsymbol{\%}$ \\
\hline $\mathbf{1}$ & Positif & 9 & 22.5 \\
$\mathbf{2}$ & Negatif & 31 & 77.5 \\
\hline \multicolumn{2}{|c|}{ Total } & 40 & 100 \\
\hline
\end{tabular}

Dari tabel di atas dapat dilihat bahwa sebagian besar responden yaitu $31 \quad(77.5 \quad \%)$ responden termasuk memiliki sikap negatif dan $9(22.5 \%)$ responden yang memiliki sikap positif.

Pada bagian ini peneliti akan membahas Gambaran dan sikap remaja putri terhadap aborsi.

\subsubsection{Pembahasan}

\section{Karasteristik Pengetahuan Responden}

Berdasarkan hasil penelitian seperti terlihat dalam tabel 5.3 dapat diketahui bahwa dari 40 responden yang diteliti sebanyak 17 responden (42,5\%) berpengetahuan kurang, 13 responden $(32,5 \%)$ dan 10 responden $(25 \%)$ berpengetahuan baik.

Pengetahuan adalah hasil dari tahu dan ini terjadi setelah orang melakukan penginderaan terhadap suatu objek tertentu (Notoatmodjo, 2003 :127).

Karena dari pengalaman dan penelitian membuktikan bahwa perilaku yang didasari oleh pengetahuan akan lebih langgeng dari pada perilaku yang tidak didasari oleh pengetahuan. Penelitian Rogers (1997) yang dikutip oleh Notoatmodjo (2003) mengungkapkan bahwa sebelum seseorang mengadopsi perilaku baru didalam diri orang tersebut terjadi suatu proses yang berurutan yaitu:

1) Awareness (kesadaran) dimana orang tersebut menyadari dalam arti mengetahui terlebih dahulu terhadap stimulus (obyek).

2) Interest, dimana orang mulai tertarik kepada stimulus atau objek tersebut, di sini sikap subjek sudah mulai timbul.

3) Evaluation (menimbangnimbang) terhadap baik buruknya tindakan terhadap stimulus tersebut untuk dirinya. Hal ini berarti sikap responden sudah lebih baik lagi.

4) Trial, dimana subjek mulai mencoba melakukan sesuatu sesuai dengan apa yang dikehendaki stimulus.

5) Adoption, dimana subjek telah berperilaku baru sesuai dengan pengetahuan, kesadaran dan sikapnya terhadap stimulus.

Adapun beberapa alasan remaja putri tidak menginginkan kehamilannya : 
1) Penundaan dan peningkatan usia perkawinan

2) Semakin dininya usia menstruasi pertama,

3) Minimnya pengetahuan tentang prilaku seksual yang dapat menyebabkan kehamilan,

4) Kehamilan yang diakibatkan pemerkosaan,

5) Alasan karir atau masih sekolah,

6) Persoalan ekonomi,

7) Kehamilan karena incest

(Wilopo dan Notoatmojo, 2005).

Pemahaman responden terhadap aborsi masih berpengetahuan buruk ada kemungkinan kejadian aborsi dikalangan remaja putri dimana remaja tidak memahami bahwa untuk hamil perlu perencanaan dan kesiapan lahir dan batin. Dan adanya anggapan siswi soal hamil adalah hal yang tidak usah dihiraukan, hal itu memacu terjadinya aborsi dikalangan remaja putri. Pengetahuan tentang kesehatan reproduksi pada remaja putri perlu mendapat perhatian ekstra agar remaja tersebut tidak terjerumus kepada hal-hal yang tidak diinginkan akibat dari dampak seks bebas.

\section{Karasteristik sikap responden}

Berdasarkan hasil penelitian seperti terlihat dalam tabel 5.4 dapat diketahui bahwa dari 40 responden yang diteliti sebanyak $23(57.5 \%)$ responden termasuk memiliki sikap negatif dan $17(42.5 \%)$ responden yang memiliki sikap positif.

Sikap merupakan respon tertutup seseorang stimulus atau objek tertentu, yang sudah melibatkan pendapat faktor pendapat atau emosi yang bersangkutan (senang- tidak senang, setuju-tidak setuju, baik-tidak baik, dan sebagainya). Champell (1950) mendefinisikan sangat sederhana, yakni "An individual's attitude is syndrome of response consistency with regard to object." jadi jelas, disini dikatakan bahwa sikap itu suatu sindroma atau kumpulan gejala dalam merespons stimulus atau objek, sehingga sikap itu melibatkan pikiran, perasaan, perhatian, dan gejala kejiwaan yang lain.

Memahami

kesehatan

reproduksi sangat penting, karena masalah kesehatan reproduksi adalah masalah besar. Mengkhawatirkan bagi kita semua apalagi dengan meningkatnya kasus-kasus IMS (infeksi menulas seksual), aborsi dan kehamilan tidak dikehendaki. Remaja putri seharusnya mampu menjaga kesehatan reproduksi dan sadar akan kewajibannya dimasa mendatang untuk melahirkan generasi anak-anak bangsa yang sehat dan berkualitas. Untuk menjaga kesehatan reproduksi remaja putri perlu dibekali pengetahuan seks, kesehatan reproduksi dan aborsi. Remaja yang berhasil menjaga alat reproduksinya besar harapan akan melahirkan anak-anaknya sehat pula kelak. Remaja putri juga harus mampu membedakan mana yang baik dan mana yang buruk tentang menjaga alat reproduksinya.

Pencegahan lebih baik segera dilakukan, untuk mencegah kehamilan remaja perlu mengetahui cara-cara pergaulan remaja pacaran sesuai norma. Inti dari pencegahan hamil masa sekolah salah satunya adalah menghindari budaya cobacoba, berhubungan dengan sikap melakukan hubungan seks semasa remaja akibat pengaruh VCD porno adalah perbuatan merugikan diri sendiri. Pemahaman siswi tentang menonton VCD porno dapat merangsang siswi berkeinginan melakukan budaya coba-coba yang 
dapat mencelakakan dirinya yaitu terlanjur bisa melakukan seks dini, yang berlanjut pada kehamilan tidak dikehendaki dan mengambil solusi aborsi yang bertentangan dengan hukum.

\subsection{Keterbatasan Penelitian}

Dalam penelitian ini masih banyak kelemahan dan keterbatasan dari beberapa aspek, diantaranya :

1. Instrumen / Alat Ukur

Pengumpulan data dengan kuesioner terdapat kalimat yang sulit dipahami oleh responden.

2. Literatur

Buku yang digunakan acuan dalam penelitian ini kurang memadai, sehingga penelitian ini masih memerlukan penyempurnaan.

\section{KESIMPULAN}

Dalam bab ini akan disimpulkan hasil penelitian untuk menjawab penelitian berdasarkan permasalahan, penjelasan dinilai dari kesimpulan kemudian untuk penyempurnaan penelitian ini perlu adanya saran.

\section{Kesimpulan}

Sebagian besar remaja putri di Madrasah Aliyah Negri Lamongan kelas XI IPS pengetahuan tentang aborsi masih kurang dan diketahui terdapat sebagian besar sikap remaja putri di Madrasah Aliyah Negeri Lamongan kelas XI IPS dapat diberi bimbingan tentang kesehatan reproduksi.

\section{Saran}

Perlu dilakukan penelitian lebih lanjut dengan harapan untuk mengkaji atau melihat faktor-faktor lain yang mempengaruhi aborsi.

Untuk institusi pendidikan, diharapkan melakukan kerja sama dengan petugas kesehatan untuk mengadakan penyuluhan tentang aborsi.

Diharapkan lebih meningkatkan peran serta petugas kesehatan dalam memberikan pelayanan kesehatan khususnya pada remaja putri.

Diharapkan lebih aktif untuk mencari pengetahuan sebanyakbanyaknya mengenai aborsi dengan bertanya kepada petugas kesehatan atau memalui buku.

\section{PUSTAKA}

Anonymous, 2007, Gugur Kandungan.

http://wikimediafoundation. org. diakses tanggal 10 April 2015.

Dianawati ,anjen.(2003).Pendidikan dan Seks untuk Remaja.Jakarta :Kawan Pustaka

Purbaningsih, 2007, Fakta Mengenai Aborsi, http://situs.kesrepro.info. diakes tanggal 10 April 2015.

Wilopo, 2004, Aborsi di Indonesia, http://www.nedstatbasic.net. diakses tanggal 10 April 2015.

Bobak, Lowdermilk, Jensen. 2004. Buku Ajar Keperawatan Maternitas / Maternity Nursing. Alih Bahasa Maria A. Wijayanti. Peter I. Anugerah, edisi 4. Jakarta : EGC.

Campbell, Donald T. 1950. The indirect assessment of social attitudes. Psychological Bulletin, Vol 47(1), Jan 1950, 15-38. doi: $10.1037 / \mathrm{h} 0054114$ 
Hanifah. L. 2007, Aborsi Ditinjau dari Tiga Sudut Pandang.

http://situs.kesrepro.in fo. diakes tanggal 10 April 2015.

Munajat, N., 2000. Risiko Reproduksi Remaja, Tim Sahabat Remaja PKBI DIY. Cetakan II. Yogyakarta: Lentera Sahaja

Notoatmojo, S. 1984, pengantar ilmu prilaku kesehatan. Jakarta: BPKM FKMUI.

Notoatmojo, S. 1997, Ilmu Kesehatan Masyarakat. Prinsipprinsip dasar Jakarta: Penerbit Rineka Cipta.

Suarta. S. 2007, Pendidikan Seksual dan Reproduksi Berbasis Sekolah. http://situs.kesrepro.in fo. diakes tanggal 10 April 2015.

Susilo. Z.K. dan Herna L. 2002, Aborsi: $\quad$ Fakta Kebutuhan dan Tantangan Serta Pengaruhnya dalam Profil Kesehatan Perempuan Indonesia. http://situs.kesrepro.in fo. diakes tanggal 10 April 2015.

Tito. 2009, Potret Remaja dalam Data.

http://kompas.com. diakes tanggal 10

April 2015.

Wilopo. S.A. 2005, Kita Selamatkan Remaja dari Aborsi dalam Rangka Pemantapan

Keluarga Berkualitas 2015. Makalah Seminar di Medan, Sumatera Utara 11 Aprl 2005.

Soekidjo, Notoatmojo. 2005, Metodologi Penelitian Kesehatan. Rineka Cipta. Jakarta.

Fakultas Kedokteran Universitas Padjadjaran Bandung. 1984. Obstetri Patologi. Elstar Ofset Bandung.

Widyastuti Yani, dkk. 2009. Kesehatan Reproduksi. Fitramaya Yogyakarta.

Sibagoriang EE, dkk.2009, Metode Penelitian. Rineka Cipta. Jakarta. 